\section{Secuencia de erupción dentaria de caninos y premolares inferiores en una muestra de niños peruanos}

\author{
Sequenseoferuptionofcuspandbicuspmandibularteethinasampleof \\ Peruvian children
}

\section{Resumen}

Se determina la secuencia de erupción de caninos y premolares inferiores, mediante un estudio transversal, en una muestra de 67 pacientes niños, 33 hombres y 34 mujeres, comprendidos entre los 8 y los 12 ańos de edad, que acudieron a la clínica Odontológica de la Facultad de Odontología de la Universidad Nacional Mayor de San Marcos entre los años 2006 y el 2011. Para el estudio se utilizaron modelos de estudio, fotografías y radiografías panorámicas de los pacientes. Los resultados más relevantes fueron que tanto para hombres como para mujeres, la secuencia de erupción que predominó fue la de 3, 4, 5. Palabras claves: Erupción dentaria, diente canino, diente premolar

Artículo Original

\section{Tomás Oriel Orellana Manrique ${ }^{1}$, Héctor Aldo Marengo Castillo ${ }^{1}$, Janet Blasa Mendoza Zapata de Neira ${ }^{1}$}

\begin{abstract}
1 Docentes del Departamento Académico de Estomatología Pediátrica. Facultad de Odontología de la UNMSM.
\end{abstract}

\section{Correspondencia:}

Tomás Oriel Orellana Manrique Av. Diez Canseco 150 Of. 304 Miraflores. Teléfono: 2415127. Lima Perú. e-mail: torellanam@unmsm.edu.pe

Fecha de recepción: 08 de abril Fecha de aceptación: 14 de junio

\section{Introducción}

La secuencia de erupción de los dientes posteriores no es uniforme como en la región anterior. La ubicación de los premolares y caninos permanentes en el maxilar inferior y su relación con las raíces de los dientes caducos y los dientes permanentes adyacentes inducen a variaciones en la secuencia de erupción.

Durante el proceso de recambio en la zona anterior, el espacio disponible en la arcada dentaria aumentará en la medida en que los caninos caducos se desplacen distal y lateralmente. La situación es diferente en la región canino-premolares donde frecuentemente la longitud de la arcada entre la cara distal del incisivo lateral permanente inferior y la cara mesial del primer molar permanente inferior no aumenta y más bien disminuye con el reemplazo de los dientes posteriores. En regla general esta dimensión es ligeramente más grande que la suma mesio-distal de los dientes permanentes y normalmente no falta espacio, sin embargo, pueden haber problemas, cuando parte del espacio es utilizado para mejorar el alineamiento de incisivos y en el caso de una secuencia de erupción desfavorable. Así mismo, la pérdida prematura de los dientes temporarios puede complicar el reemplazo final de los dientes posteriores. $^{1}$

El objetivo del presente estudio fue determinar la secuencia de erupción de caninos y premolares inferiores de una muestra de nińos que acuden a la clínica odontológica de la Facultad de Odontología de la UNMSM y compararlo con los estudios de otras poblaciones.

\section{Calcificación y erupción}

La erupción es el movimiento del diente hacia el plano oclusal, comienza de manera variable, pero no hasta que haya comenzado la formación de la raíz. Durante la erupción de los dientes de reemplazo, ocurren muchas actividades simultáneamente: el diente primario se reabsorbe, la raíz del permanente se alarga, el proceso alveolar aumenta en altura y el diente permanente se mueve en el hueso. ${ }^{2}$

Los dientes permanentes no comienzan movimientos eruptivos hasta después que se ha completado la corona. Pasan por la cresta del proceso alveolar cuando se ha formado aproximadamente dos tercios de la raíz (estadío 8 de Nolla) y perforan el margen gingival cuando más o menos tres cuartos de la raíz está formado (estadío 9 de Nolla). Las raíces habitualmente se completan unos pocos meses después de lograr la oclusión. $^{2}$

\section{Factores que regulan $y$ afectan la} erupción

Tanto la secuencia como la regulación en tiempo de la erupción, parecen estar muy determinadas por los genes. Además, hay secuencias y regulaciones de erupción que son típicas para ciertos grupos raciales; por ejemplo, en los europeos y los americanos de origen europeo, sus dientes tienden a erupcionar más tarde que en los negros americanos y los amerindios. 
Las influencias nutricias sobre la calcificación y erupción son relativamente mucho menos significativas que las genéticas, porque es solamente en los extremos de la variación nutricia que se han demostrado los efectos sobre la erupción dentaria.

Los trastornos mecánicos pueden alterar el plan genético de erupción, al igual que los procesos patológicos localizados. Las lesiones periapicales, como la pulpotomía de un molar primario, acelerará la erupción del premolar de reemplazo. Si el diente primario es extraído después que el sucesor permanente ha comenzado movimientos activos de erupción (estadío 6 de Nolla o posteriores), el permanente erupcionará más temprano. Si el primario es extraído antes del comienzo de los movimientos eruptivos del permanente (antes del estadío 6 de Nolla), es muy probable que el permanente sea demorado en su erupción, ya que el proceso alveolar puede volver a formarse sobre el diente sucesor, haciendo la erupción más difícil y lenta. También se ha demostrado que el apińamiento de los dientes permanentes afecta en grado pequeño su velocidad de calcificación y erupción. ${ }^{2}$

\section{Regulación y variabilidad de la erup- ción}

La erupción tiende a aparecer más temprano en el negro americano y en las poblaciones indias y asiáticas que en los americanos de origen europeo. La regulación está correlacionada dentro de una dentición; esto es, los niños en quienes cualquier diente erupciona temprano o tarde, tiende a adquirir otros dientes igualmente temprano o tarde.

\section{Diferencias de sexo}

Excepto para los terceros molares, en las niñas erupcionan los dientes permanentes a un promedio de aproximadamente 5 meses más temprano que los varones.

\section{Secuencia de erupción}

La secuencia de erupción de los dientes permanentes es tan importante como las consideraciones de espacio en el arco dental $^{3}$. La secuencia aparente del desarrollo de la calcificación no es una pista segura a la secuencia de aparición en la boca, ya que los factores que regulan y afectan la velocidad de erupción varían entre los dientes. Hay una amplia variabilidad en la secuencia de llegada de los dientes en la boca; algunas de las va- riaciones son importantes clínicamente. En el maxilar superior, las secuencias 6-1-2-4-3-5-7 y 6-1-2-4-5-3-7 cuentan para casi la mitad de los casos, mientras que en la mandíbula, las secuencias 2-3-4-5-7 y (6-1)-2-4-3-5-7 incluyen más del $40 \%$ de todos los nińos.

Una norma es tratar de conservar los lados derecho e izquierdo con el mismo ritmo de erupción. No deberá darse demasiada importancia a la variación del orden si parece haber suficiente espacio. Después de la pérdida de los segundos molares deciduos, existe un ajuste de la oclusión de los primeros molares permanentes. La tendencia a la clase II existente en toda la dentición decidua y mixta deja de existir. ${ }^{4}$

Una de las implicaciones clínicas de esta diferencia respecto a la época de erupción es la prevalencia de impactación dental entre el arco superior y el inferior. En la dentición superior, es común observar un canino impactado, ya que es un diente que "cambia poco" cuando falta espacio. En el arco inferior el diente impactado más frecuentemente es el segundo premolar, debido a que hace erupción después del canino y del segundo premolar. ${ }^{3}$

Los caninos permanentes son formados inicialmente más cerca del borde inferior de la mandíbula que el segundo premolar y esta diferencia es aún más marcada a nivel del primer premolar (Fig 1). En la fase preeruptiva, los gérmenes de los premolares se encuentran más cerca del plano oclusal que los caninos permanentes, quienes sobrevienen los dientes más largos de la mandíbula. La punta del canino permanente se encuentra en situación lingual en relación con el ápice del canino temporal, sin embargo su relieve vestibular hace prominencia y es fácilmente palpable. Los premolares son formados entre las raíces de los molares temporales. Antes de la erupción, la cara distal del canino permanente está en contacto o muy cerca de la parte cervical mesial del primer premolar. ${ }^{1}$

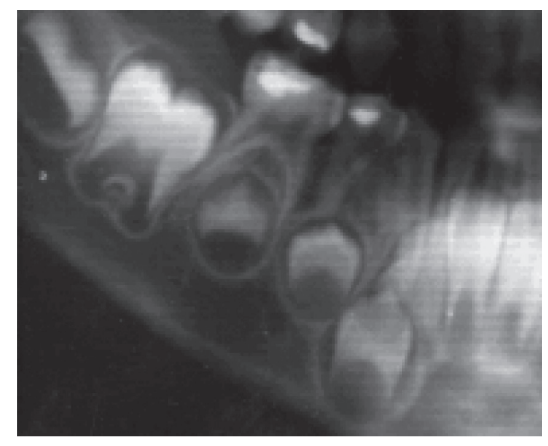

Fig. 1. Gérmenes de caninos y premolares.

\section{Distancia intercanina}

Después de la erupción de los incisivos, el aumento de la dimensión intercanina inferior es mínima, coincidiendo con la erupción de los caninos permanentes, tanto en hombres como en mujeres; esto prácticamente termina a los 10 ańos de edad. Clínicamente el crecimiento intercanino inferior está terminado en las últimas etapas de la dentición mixta.

\section{Espacio libre de Nance}

En el maxilar inferior, el ancho combinado del canino deciduo, el primer molar deciduo y el segundo molar deciduo es aproximadamente $1.7 \mathrm{~mm}$ mayor que el ancho combinado del canino permanente y primero y segundo premolares. En el maxilar superior, la diferencia combinada de esta dimensión tiene un promedio de $0.9 \mathrm{~mm}$. Esta diferencia de espacio para cada segmento maxilar se llama el espacio libre (Leeway Space) de Nance. ${ }^{4}$

La oclusión en el "plano terminal" de los primeros molares permanentes en la dentición mixta es una maloclusión temporal, y retorna a una relación clase I al moverse el molar inferior hacia adelante mucho más que el superior. ${ }^{3}$

Morón, en un estudio realizado en escolares de la etnia indígena Wayúu en Venezuela, encontró que la secuencia de erupción en la arcada inferior fue de 34, - 44,33,-43, 45-35: primer premolar, canino, segundo premolar. ${ }^{5}$

En América Latina, existen escasas investigaciones que posibiliten demostrar las diferencias étnicas en el proceso de erupción. Sin embargo, estudio realizado en Curazao, Antillas Neerlandesas, en niños negros de las escuelas primarias, indicó que los dientes permanentes erupcionan en una edad más temprana que las edades reportadas para los niños blancos.

Con relación al sexo, la generalidad de los estudios realizados señalan su vinculación con el proceso de erupción, demostrando como ésta ocurre primero en las mujeres que en los varones, lo cual está asociado con factores hormonales, debido a la maduración más temprana en las niñas.

El patrón normal de erupción dental es variable tanto en la dentición temporal como en la permanente, observándose mayores modificaciones en la cronología que en la secuencia, la cual sigue un orden más estricto de erupción. ${ }^{5}$ 
Romero, en un estudio sobre prevalencia y secuencia de erupción en el maxilar inferior en nińos y niñas en la UGMA en el 2006, encontró que en varones la secuencia de erupción era de 4, 5, 3 con una prevalencia del primer premolar de $79 \%$ y en mujeres la secuencia de erupción era de 4, 3, 5 con una prevalencia del primer premolar del $86 \%{ }^{6}$

Gonzales ME citado por Jara ${ }^{7}$, en un estudio en una población chilena, encontró según su tabla que presenta, que la secuencia de erupción de la zona posterior mandibular era de 4, 3, 5 en varones y de 3, 4, 5 en mujeres. ${ }^{7}$

Hurme, citado por Moyers realizó un estudio matemático de la erupción dentaria en caucásicos, determinando una secuencia de erupción de 3, 4, 5. Considerada como una secuencia de erupción más favorable, ya que si los caninos erupcionan primero, tienden a mantener el perímetro del arco impidiendo la inclinación lingual de los incisivos inferiores. ${ }^{2}$

\section{Material y métodos}

Se realizó un estudio de tipo descriptivo y transversal, con un muestreo no probabilístico. El universo del estudio estuvo conformado por todos los pacientes niños que acudieron en busca de tratamiento odontológico a la Clínica de la Facultad de Odontología de la UNMSM desde el año 2006 hasta el año 2011. La muestra estuvo conformada por radiografías panorámicas, modelos de estudio y fotografías de 67 pacientes niños, 33 de sexo masculino y 34 de sexo femenino, cuyas edades estuvieron comprendidas entre los 8 y los 12 ańos de edad. La recolección de la información se realizó en base a 6 posibles secuencias de erupción: $3,4,5 ; 3,5,4 ; 4$, 3,$5 ; 4,5,3 ; 5,3,4 ; 5,4,3$. En el caso que dos dientes erupcionaban como los primeros al mismo tiempo en una hemiarcada, se les dio igual puntaje.

\section{Resultados}

En el cuadro $\mathrm{N}^{\circ} 1$ se puede apreciar que la secuencia de erupción que predominó en varones fue la de 3, 4, 5 , obteniéndose el $38.15 \%$ (Fig. 2). Sin embargo, si nos referimos a la prevalencia del primer diente en erupcionar, le correspondería al primer premolar inferior.

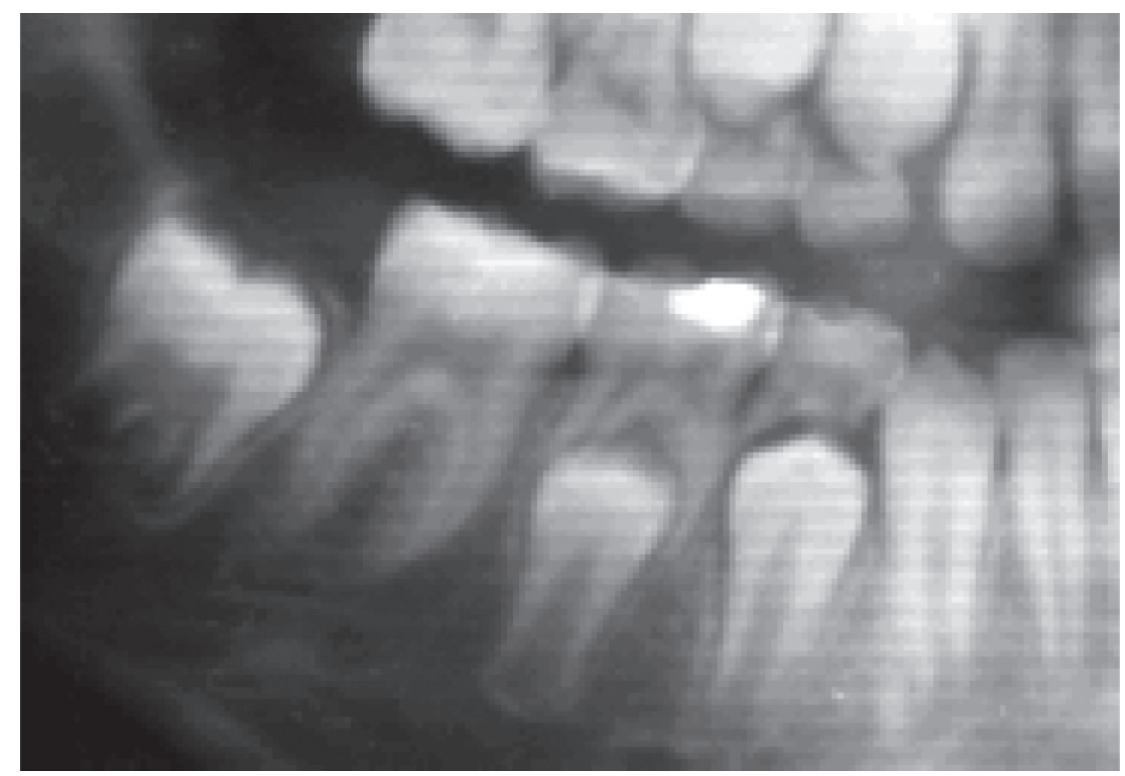

Fig. 2. Secuencia de erupción 3, 4, 5.

Tabla 1 Secuencia de erupción caninos permanentes y premolares inferiores en varones.

\begin{tabular}{ccccc}
\hline $\begin{array}{c}\text { Secuencia de } \\
\text { erupción }\end{array}$ & $\begin{array}{c}\text { Hemiarcada } \\
\text { derecha }\end{array}$ & $\begin{array}{c}\text { Hemiarcada } \\
\text { izquierda }\end{array}$ & Arcada Inferior & Porcentaje \\
\hline $3,4,5$ & 15 & 14 & 29 & 38.15 \\
$3,5,4$ & 1 & 0 & 1 & 1.31 \\
$4,3,5$ & 13 & 12 & 25 & 32.89 \\
$4,5,3$ & 5 & 5 & 10 & 13.15 \\
$5,3,4$ & 2 & 2 & 4 & 5.26 \\
$5,4,3$ & 4 & 3 & 7 & 9.21 \\
Total & 40 & 36 & 76 & 100 \\
\hline
\end{tabular}

Tabla 2 Secuencia de erupción de caninos permanentes y premolares en mujeres

\begin{tabular}{ccccc}
\hline $\begin{array}{c}\text { Secuencia de } \\
\text { erupción }\end{array}$ & $\begin{array}{c}\text { Hemiarcada } \\
\text { derecha }\end{array}$ & $\begin{array}{c}\text { Hemiarcada } \\
\text { izquierda }\end{array}$ & Arcada Inferior & Porcentaje \\
\hline $3,4,5$ & 21 & 25 & 46 & 53.48 \\
$3,5,4$ & 1 & 0 & 1 & 1.16 \\
$4,3,5$ & 12 & 12 & 24 & 27.90 \\
$4,5,3$ & 1 & 4 & 5 & 5.81 \\
$5,3,4$ & 1 & 0 & 1 & 1.16 \\
$5,4,3$ & 4 & 5 & 9 & 10.46 \\
Total & 40 & 46 & 86 & 100 \\
\hline
\end{tabular}

En el cuadro $\mathrm{N}^{\circ} 2$, se aprecia que en las mujeres, la secuencia de erupción en el maxilar inferior que predominó fue la de 3, 4, 5, registrándose el $53.48 \%$. La prevalencia del primer diente en erupcionar le correspondió al canino inferior.

\section{Discusión}

Según Hurme, para la raza caucásica y europea, en la arcada dentaria inferior, el canino permanente es el que emerge primero, pese a encontrarse a una mayor distancia del plano oclusal, luego emerge el primer premolar y por último el segundo premolar.
En el presente estudio, la secuencia de erupción que predominó tanto para el sexo masculino como para el femenino fue de 3, 4, 5; lo que significa que en esta secuencia primero erupciona el canino permanente, luego el primer premolar y por último el segundo premolar al igual que los descritos por Hurme. Gonzales ME citado por Jara ${ }^{7}$, en un estudio de una población chilena, encontró también una secuencia de erupción de 3, 4, 5, pero en mujeres. Otros estudios realizados en América Latina como el de Romero $^{6}$ quien encontró una secuencia de erupción de 4, 5, 3 en varones y 4, 3, 5 en mujeres, y el de Morón quien 
reportó una secuencia de erupción de 4 , 3, 5. En lo que respecta a las hemiarcadas derecha e izquierda, no se encontró diferencias relevantes.

\section{Conclusiones}

Según los resultados encontrados en el presente estudio se concluye que la secuencia de erupción en la arcada inferior en los niños que acuden a la clínica Odontológica no difiere de la secuencia de erupción de la raza caucásica, correspondiendo a la secuencia de $3,4,5$. (canino, primer premolar, segundo premolar), tanto para hombres como para mujeres.

\section{Referencias bibliográficas}

1 Van der Linden F. P. G. M. De la denture temporaire a la denture permanente. Rev D'ODF 1979; 13.

2 Moyers R. Manual de Ortodoncia. Cuarta edición: Editorial Médica Panamericana; 1990.

3 Chaconas J. Ortodoncia. Editorial El Manual Moderno: USA; 1980.

4 Graver T.M. Ortodoncia Teoría y Práctica. Tercera Edición. Nueva Editorial Latinoamericana: México; 1974.

5 Morón A. Cronología y secuencia de erupción de dientes permanentes en escolares Wayuu Parroquia Idelfonso Vásquez Municipio Maracai- bo - Estado Zulia. Acta Odontológica Venezolana 2006; 44 (1).

6 Romero M A. Prevalencia y secuencia de erupción en el maxilar inferior en pacientes escogidos del diplomado de Ortodoncia Interceptiva U.G.M.A. 2006. Revista Latinoamericana de Ortodoncia y Odontopediatría. Julio 2008.

7 Jara, S.L. Cronología de la erupción dentaria permanente en pacientes con síndrome de Down. Rev Chil Pediatria 1992; 63 (2): 89-95. 